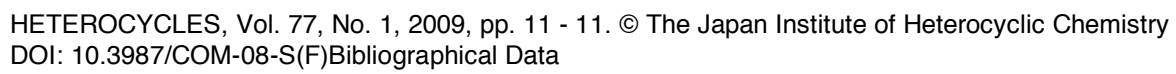

\title{
BIBLIOGRAPHICAL DATA
}

Name: $\quad$ Keiichiro Fukumoto

Home Address: 1-8-23, Asahigaoka-tsutsumi, Izumi-ku, Sendai, Japan

Date \& $\quad$ February 10, 1934

Place of Birth: Shodo Island, Kagawa, Japan

Education \& $\quad$ B. Sc. : Osaka University, 1956

Degrees : Ph. D. : Osaka University, 1964

\section{Employment}

Experience :

1959-1972 Assistant Professor, Tohoku University

1964-1965 Postdoctoral Research Fellow: University of Alberta (Professor S. Masamune)

1965-1966 Postdoctoral Research Fellow: University of Sussex (Professor A. I. Scott)

1972-1981 Associate Professor, Tohoku University

1981-1997 Professor, Tohoku University

1997 Emeritus Professor, Tohoku University

Awards

1976 The Pharmaceutical Society of Japan (The PSJ) Award for Young Scientists

1993 Academic Award of the Society of Synthetic Organic Chemistry, Japan

1996 The PSJ Award

$2000 \quad$ Medal of Honor with Purple Ribbon 